\title{
LXXV. On the Rev. J. G. MacVicar's experiment on vision
}

\section{J.T. Graves Esq. A.M.}

To cite this article: J.T. Graves Esq. A.M. (1837) LXXV. On the Rev. J. G. MacVicar's experiment on vision, Philosophical Magazine Series 3, 10:62, 370-373, DOI: 10.1080/14786443708649177

To link to this article: http://dx.doi.org/10.1080/14786443708649177

曲 Published online: 01 Jun 2009.

Submit your article to this journal $๘$

Џ Article views: 2

Q View related articles $\asymp$ 


\section{[ 370 ]}

LXXV. On the Rev. J. G. MacVicar's Experiment on Vision. By J. T. Graves, Esq., A.M.*

THE ordinary laws of reflection and perspective are sufficient to account for the radiated appearance described by the Rev. Mr. MacVicar (antè, p. 234,) without the hypothesis of any hitherto unknown symmetrizing power in the eye.

No radiation is observed when the particles are spread at whatever distance over a non-reflecting surface, or are placed in immediate contact with a reflecting one. Now if a reflecting surface in the required position of contiguous parallelism to the plane of the dust contributes to the success of the experiment, it is surely à priori likely that it does so rather by the addition it makes to the objects of vision than by any induced alteration in the mechanism of the eye, affecting the mode in which the former objects, if seen alone, would be viewed. Accordingly we are led to consider the actual nature of the picture before us when the phænomenon is observed.

When we survey with one eye dust spread over a common looking-glass, we see not only the particles themselves but their images reflected by the mercury (wherever those images are not intercepted by the position of other particles on the glass), and both classes of objects, from their general similarity of appearance, are referred to the same plane. Upon further examination we shall perceive that every reflected image when referred to the external surface of the looking-glass, appears in a direct line between its prototype and the point of that external surface nearest the centre of the eye. In making this observation, we may use with advantage small shots or seeds instead of flour or other finely-powdered substances, and we may put out of consideration the fainter and scarcely perceptible images formed by reflection at the external surface, as they do not materially alter the general picture. Now the appearances above described might have been predicted as the necessary results of known principles.

Within the ordinary limits of the sphere of sight, it is an observed approximate law of vision, whether direct or indirect, that when a pencil of rays diverging from any point enters the pupil, an image is seen in the direction of the line drawn from that focal point through the centre of the eye. Again, it is an observed law of light that the angles of incidence and reflection are equal and in the same plane. From the latter law it follows by simple geometrical reasoning, that all the rays proceeding from any point and reflected by a

* Communicated by the Author. 
plane mirror diverge after reflection from an opposite corresponding point equidistant from the mirror; and it also follows that the line joining the conjugate points from which direct and reflected pencils diverge is perpendicular to the plane of the mirror. Hence if we have a perspective plane parallel to the plane of the mirror, and carrying all the objects to be reflected, the line of direction in which, by the preceding law of vision, any reflected image is seen will cut the line which joins the object and the point of the perspective plane nearest the centre of the eye, in the ratio which twice the distance of the perspective plane from the mirror bears to the distance of the same plane from the centre of the eye. While the head remains unmoved, the rolling motion of the eye does not affect the position of its centre, and consequently the apparent positions of the reflected images as well as those of their direct objects remain unaltered.

The relative position of the particles and their images to the point of the perspective plane nearest the centre of the eye will account for the radiated appearance. The interval between each particle and each image produces a short line pointing in a given direction. The multitude of such pointers and the multitude of instances in which separate pointers combine to form a prolonged continuous line radiating to a given centre, actually produce in the spectrum a predominant symmetry, which the mind, without any previous peculiar adjustment of the eye, can scarcely fail to notice.

We may form a similar radiating group of objects of vision, which shall not have the disadvantage of being altered as to half its components by every motion of the centre of the eye, if we first dot a sheet of paper indiscriminately, and then mark a second system of dots so related to the former that the interval between each pair of conjugate dots may tend in direction to an assumed centre and be proportional in length to its mean distance from that centre. Here it is evident on inspection that no extraordinary symmetrizing power is required to perceive the radiation. We may observe, however, that if we mark the second system only to a certain distance, around the assumed centre, a principle of continuity will incline us to trace the resulting radiation beyond that distance, by drawing our chief attention to the exterior points in the original system in so far as they continue the discovered symmetry. Again, if we mark the first system of dots in blue, and the second in red, the radiation resulting from the combined position of the systems will fix our attention on the parts of each system in so far as they contribute to the joint effect, so that when the two systems are simultaneously viewed as separate 


\section{On the Rev. J. G. MacVicar's Experiment on Vision.}

wholes, they will each appear to radiate. If this were repeated often enough, we might perhaps afterwards be able to trace a radiation in either system unbacked by the guidance of the other, for the eye is predisposed to recur to that attitude in which while previously looking at an object symmetry has been perceived.

The eye has parts severally capable within certain limits of distinct adjustments voluntary or instinctive. From natural conformation, acquired habit, or the present immediate operation of metaphysical causes, the eye seeing simultaneously the whole of a given field, may probably possess a superior facility of severally adjusting its mechanism by parts corresponding to parts of the field in some manners rather than in others, and may also be predominantly inclined to alter its sphere of vision in particular directions. Hence in a group of objects in which different laws of arrangement are discoverable, one attitude of the eye may be the best adapted for the discovery of one law and another for that of a different one. For example, let a sheet of paper be dotted in such a manner that each surrounded dot may be the centre of a regular hexagon, of which the surrounding dots mark out the apices; then the rows, in which the mind will roithout effort arrange the dots, will vary with the direction of the eye, and, with effort, the grouping may be altered without altering the field of vision. $\AA$ similar observation may be made in looking at large piles of cannon balls. Not the imagination merely but the plastic eye of Phidias is at work while he is delineating the Venus in the yet uncarved marble before him. That visual prejudice which consists in a tendency to adjust the respective parts of the eye in particular modes, not naturally suggested by the general impression resulting from the objects presented to those parts, is a defect exemplified in persons who see ghosts in the window-curtains and faces in the burning embers.

Though the interesting experiment which Mr. MacVicar has introduced to the public in the pages of this Magazine, does not seem adapted to illustrate the changes that take place in the eye, corresponding to the changes that take place in the grouping and symmetry seen in the subjective spectrum of a given object, it may be of use for a purpose of scarcely inferior curiousness and importance; for if we compare what we see in surveying the powdered looking-glass with both eyes, with the phænomena which we should expect to result from the separate and different spectra due to each eye singly, we may perhaps be enabled to throw light on some obscure processes in the physiological mechanism of binocular vision. This, however, is an inquiry deserving consideration by itself. 
For the present let it suffice to have indicated the general causes of the radiated appearance seen in Mr. MacVicar's experiment.

J. T. Graves.

[Communications on the same subject have been received from Mr. H. S. Peacock of London, Mr. William George Horner of Bath, Mr. Robert Wilson of Glasgow, Mr. J. De C. Sowerby of Camden Town, Mr. G. Dodd of London, and Mr. G. H. Hoffman, Surgeon, of Margate. They all agree in referring the phænomenon in question to the principles of reflection and perspective explained in the preceding paper, and the three latter gentlemen respectively mention that they had observed the radiated appearance for considerable periods before the publication of Mr. MacVicar's letter.-EDIT.]

LXXVI. On the Composition of the Right Rhombic BarytoCalcite, the Bicalcarco-Carbonate of Baryta of Dr.Thomson. By James F. W. Johnston, A.M., F.R.S.E., Professor of Chemistry and Mineralogy in the University of Durham.*

$\mathrm{N}$ the sixth volume of this Journal, p. 1, 1 described a mineral occurring in the lead-mine of Fallowfield near Hexham, Northumberland, which I had found on analysis to be a true baryto-ealcite, though having a form wholly irreconcileable with the doubly oblique prism of the original barytocalcite of Brooke.

Since the publication of this description, Dr: Thomson of Glasgow inserted in the Records of Science, vol. i. p. 369, and more recently in his System of Mineralogy, vol. i. p. 14i, an account of a mineral from Bromley Hill mine near Alston, having the same specific gravity and the same crystalline form as my new baryto-calcite, but having a different composition.

My attention was first drawn to this circumstance by my friend Mr. Brooke, who at once recognised my second form of baryto-calcite in the mineral of Dr. Thomson, and aware of the importance of a knowledge of the true composition of this mineral to the doctrine of isomorphism, requested to know whether I had actually analysed my specimens from Fallowfield. $\mathrm{My}$ analysis gave the formula $\dot{\mathrm{Ca}} \ddot{\mathrm{C}}+\dot{\mathrm{Ba}} \ddot{\mathrm{C}}$, that of Dr.Thomson $2 \dot{\mathrm{Ca}} \ddot{\mathrm{C}}+\dot{\mathrm{Ba}} \ddot{\mathrm{C}}$, and hence the name Bicalcareo-carbonate of Baryta which he has assigned to the mineral.

Unwilling to leave the matter in doubt I repeated my analysis of the Fallowfield mineral.

* Communicated by the Author. 